\title{
PARADIGMA MEMBANGUN GENERASI EMAS INDONESIA TAHUN 2045
}

\author{
Antonius Remigius Abi \\ Program Studi PGSD Universitas St. Thomas, Jl. Setiabudi Medan \\ email: antonius@gmail.com
}

\begin{abstract}
In 2045 Indonesia will enter the golden generation. It requires Indonesia to prepare its young generation ready to face the moment well so that gold generation become tough and think forward but always hold firmly Pancasila values. The 2045 gold generation is the hope of the Indonesian nation future. Education is a very central medium in preparing the gold generation, especially its character. The character that must be built must be holistic and comprehensive based on Pancasila. Education not only transfers knowledge but also values primarily character. Characters implanted in the golden generation must be based on three aspects namely the value of honesty, the value of truth and the value of justice.
\end{abstract}

Keywords: Paradigm, Golden Generation, character

\begin{abstract}
Abstrak: Tahun 2045 Indonesia memasuki generasi emas. Hal tersebut menuntut Indonesia untuk mempersiapkan generasi mudanya siap menghadapi momen tersebut dengan baik, sehingga generasi emas menjadi tangguh dan berfikir maju akan tetapi selalu memegang teguh nilai-nilai Pancasila. Generasi emas 2045 merupakan harapan masa depan bangsa Indonesia. Pendidikan merupakan media yang sangat sentral dalam mempersiapkan generasi emas terutama karakternya.Karakter yang harus dibangun haruslah bersifat holistik dan komprehensif berbasis pancasilais.Pendidikan tidak hanya mentransfer ilmu tetapi juga nilai-nilai terutama karakter.Karakter yang ditanamkan pada diri generasi emas haruslah berbasis tiga aspek yakni nilai kejujuran, nilai kebenaran dan nilai keadilan.
\end{abstract}

Kata kunci:Paradigma, Generasi Emas, karakter

Momentum paling penting dalam perjalanan sejarah bangsa Indonesia terjadi pada tahun 2045, karena pada saat itu Indonesia memasukiusia 100 tahun kemerdekaannya. Harapan besarnya bahwa pada tahun 2045 Indonesia akan diisi oleh generasi yang memiliki usia produktif dalam jumlah yang mayoritas di antara usia penduduk sekarang masih jenjang sekolah dasar (SD), Sekolah menengah pertama (SMP)dan Sekolah Menengah Atas (SMA). Kini berdasarkan jumlah angkatan kerja menurut jenjang pendidikan tertinggi 2015 mayoritas tamatan Sekolah Dasar (SD) yakni 32.492 .539 orang (26Ï5\%). Angkatan kerja yang berasal dari universitas (sarjana) berjumlah 10.210.481 orang (8.3\%). Jumlah terendah berasal dari jenjang diplomaÏ yakni 3.337.985 orang (2.75\%) (Priandono dkk 2016).

Tantangan yang lebih besar pada saat ini adalah krisis sumber daya manusia terutama dalam krisis karakter. Krisis karakterkarena pendidikan lebih berorientasi pada hal-hal yang teknispragmatis yang berorientasi hasil atau manfaat atau kegunaandaripada yang lebih mendasar (filosofinya) yakni pendidikan adalah proses pemanusiaan dan pembudayaan.Salah satu contoh karakter sekolah yang berorientasi pada praktis pragmatis adalah "Sekolah atau kampus penuh dengan hiruk pikuk dan ramai seperti pasar karena berbagai "produk" dijual atau dipamerkan di sana" (Darmaningtyas, 2015: 4). Dengan demikian, praksis pendidikan yang memiliki tujuan untuk mencerdaskan manusia Indonesia menjadi kabur karena orientasi sekolah tidak menyentuh aspek filosofi dari pendidikan merupakan proses memanusiakan dan membudayakan.

Apabila pendidikan lebih berorientasi pada hasil atau manfaat maka praksis pendidikan lebih menghamba pada kepentingan kapital yang tidak manusiawi, bahkan cenderung mereduksi kemanusiaan sebagai bagian dari sumber daya 
ekonomi saja, bukan sebagai manusia yang bebas, merdeka dan bermartabat (Darmanigtyas, 2008:145-146). Praksis pendidikan yang demikian akhirnya melahirkan sikap-sikap negatif misalnya tawuran antar pelajar atau antarmahasiswa, meningkatnya kenakalan remaja termasuk penyalahgunaan narkoba, dan maraknya pergaulan bebas.Generasi muda terjebak dalam lingkaran apatisme, hedonisme dan mungkin saja ini karena ketidaksiapan karakter generasi muda dalam menghadapi era globalisasi.

Generasi muda lebih cenderung mementingkan diri sendiri, melemahnya nilai kebersamaan (kecenderungan individual, egois, tidak peduli), melemahnya sikap sabar (kecenderungan anarkis, jahat, instan), melunturnya nilai dan norma agama dan sosial (kecenderungan menghalalkan segala cara), melunturnya nilai nasionalisme, (kecenderungan primordial), kurang menghargai diri sendiri, kurang mengoptimalkan potensi diri (kecenderungan malas) kurang percaya diri (kecenderungan mudah diadu domba), dan tidak konsisten serta kecenderungan munafik.

Demikian digambarkan Darmaningtyas (2005:40), dikalangan mahasiswa lebih suka yang pragmatis, materialistik, serba instan, suka mencari jalan pintas dan berprilaku otoriter, hanya sedikit mahasiswa yang memiliki idealis dan integritas yang tinggi sebagai calon dosen, peneliti, jurnalis maupun profesi lainnya.

Menurut Watimena terdapat dua tantangan yang dihadapi dalam dunia pendidikan di Indonesia akan esensi pendidikan. Pertama, manusia yang keluar dari sistem pendidikan yang lupa akan dirinya sendiri ini jelaslah bukan manusia yang bisa membawa perubahan ke arah yang lebih baik di masyarakat. Bahkan dapat dikatakan dengan lugas, lemahnya moral bangsa ini jelas merupakan kegagalan sistem pendidikan yang selama ini ada, yakni pendidikan yang kehilangan esensinya sendiri.Dua, pendidikan yang kehilangan esensinya, dan semata memfokuskan dirinya untuk mengabdi pada kepentingan-kepentingan eksternal, yang seringkali tidak sesuai dengan visi pendidikan itu sendiri, akan membuat pendidikan menjadi penyiksaan. Pendidikan menjadi keterpaksaan yang dijalani oleh para siswa dengan murung dan gelisah.

Krisis karakter di kalangan generasi muda menurut Belfferik adalah krisis karakter dalam perspektif nomotesis maupun ideografis. Persektif nomotesis mengisyaratkan Pancasila sebagai sumber karakter Negara Kesatuan Republik Indonesia yang mengandung nilai-nilai universal yakni ketuhanan, kemanusiaan, persatuan, kerakyatan dan keadilan sosial.Perspektif nomotetis harus kuatkarena sangat berpengaruh pada sikap, polapikir, komitmen dan kompetensi. Sementara perspektif ideografis mengacu pada kemampuan produktif dan kreatif secara individual. Interaksi nomotesis dan ideografis terintegrasi dalam sikap positif, polapikir esensial, komitmen normatif dan kompetensi abilitas.

Melemahnya perpsektif nomotesis dan ideografis dari generasi muda karena pendidikan terlalu menekankan teknis, pragmatis, dan ideologis dari pada filosofi pendidikan itu sendiri.Artinya tujuan pendidikan yang dirumuskan lebih pada melegitimasi kebijakan-kebijakan pendidikan yang memperlancar arus globalisasi ekonomi.Manusia (generasi emas) yang cerdas dapat membangun kehidupannya lebih baik adalah manusia yang mementingkan kepentingan umum, menghargai kebersamaan, sabar, memiliki nilai dan norma agama, nasionalis, patriotis, percaya diri, berkeadilan, menghargai diri, konsisten dan tidak munafik. Dapat juga dikatakan manusia yang cerdas adalah manusia yang unggul, bermoral, religius, cerdas, nasionalis, patriotisme serta berdaya saing global.

\section{ESENSI FILSAFAT ILMU PENDIDIKAN}

Hakikat dari filsafat ilmu pendidikan adalah pendidikan yang membebaskan.Pendidikan yang membebaskan dapat diartikan sebagai pendidikan yang membantu generasi emas menemukan seluruh potensi diri agar menjadi lebih manusiawi. Perpsektifyang lebih manusiawi Suparlan (2005:93-95), menyatakan bahwa esensi filsafat pendidikan harus dikembalikan pada tiga tahapan yakni aspek ontologis, aspek epistemologis, dan aspek etika.

Pada tataran ontologis proses pendidikan dengan penekanan pendirian "filsafat hidup", merupakan suatu pandangan hidup yang dijiwai nilai kejujuran. Dengan adanya hal tersebut maka diharapkan akan ada pertumbuhan dan perkembangan kematangan spiritual generasi emas berupa wawasan luas yang menyeluruh dan padu meliputi asal usul, eksistensi dan tujuan hidup. Secara ontologis pendidikan selalu terkait dengan hakikat keberadaan manusia.Artinya tanpa manusia pendidikan itu bukan apa-apa sebaliknya 
tanpa pendidikan mustahil manusia mampu mempertahankan kelangsungan hidupnya.Pada esensi abstrak, pendidikan bernilai universal yaitu pendidikan memang mutlak harus ada dan berlaku bagi setiap manusia.Sasaran pendidikan merupakan proses untuk memanusiakan manusia. Pada esensi potensial pendidikan, pendidikan merupakan suatu daya yang mampu membuat manusia (generasi emas) berada dalam kepribadiannya sebagai manusia kreatif kepribadian yang kreatif. Pada esensi kongkrit, pendidikan merupakan daya yang mampu membuat setiap generasi emas berkesadaran utuh terhadap hakikat keberadaannya berdasar pada nilai asal usul dan tujuan kehidupannya.

Pada aspek epistemologis pendidikan menekankan sistem kegiatan pendidikan pada "pembentukan sikap ilmiah", suatu sikap yang dijiwai nilai kebenaran. Sikap ilmiah ini diharapkan adannya pertumbuhan dan perkembangan kematangan intelektual generasi emas berupa kreativitas dan keterampilan hidup.

Pada aspek etika pendidikan menekankan sistem kegiatan pendidikan pada "pengembangan prilaku bertanggung jawab", suatu prilaku yang dijiwai oleh nilai keadilan. Dengan perilaku tanggung jawab diharapkan tumbuh kematangan emosional bisa tumbuh dan berkembang yakni kemampuan pengendalian diri generasi emas untuk tidak melakukan perbuatan yang melampaui batas.

Ketiga aspek tersebut di atas memiliki keterkaitan yang sangat erat satu dengan yang lainnya secara kausalitas. Kematangan ontologis akan melahirkan generasi emas yang selalu dijiwai nilai kejujuran dalam seluruh hidupnya, dengan kematangan epistemologis akan melahirkan generasi emas yang dijiwai nilai kebenaran, dan dengan kematangan etika akan melahirkan generasi emas yang dalam perilaku hidupnya dijiwai nilai keadilan. Nilai kejujuran, kebenaran, dan keadilan yang melekat pada generasi emasakan melahirkan generasi emas yang dapat berlaku arif bagi diri sendiri, sesama, alam maupun Causa Primanya.

Prinsipnya ruang lingkup pendidikan harus meliputi seluruh segi kehidupan generasi emas dan berlangsung terus-menerus.Pendidikan sesungguhnya berawal dari kehidupan keluarga, kemudian secara efektif, efisien dan metodik serta sistemik dilanjutkan di sekolahandan pada akhirnya dilanjutkan dalam kehidupan sosial di masyarakat.
Darmaningtyas (2005:41) mengungkapkan pendidikan yang harus dilakukan adalah pendidikan yang mengajarkan berpikir rasional, bersikap kritis, dan konsisten, berjiwa merdeka, dan menanamkan nilai-nilai kebenaran, kejujuran, kepekaan, kejuangan, keindahan, kearifan, kebersamaan, demokrasi, kemanusiaan, dan kemerdekaan.

\section{FILSAFAT PENDIDIKAN INDONESIA}

Persoalan filosofi pendidikan di Indonesia pascareformasi menjadi persoalan krusial. Alasannya munculnya berbagai kelompok kepentingan yang ingin mengegolkan aspirasinya agar menjadi platform seluruh bangsa. Citra diri individu melebur ke dalam sistem politik yang sentralistik, hegemonik dan totalitarian (Darmaningtyas, 2008:143). Rumusan tujuan pendidikan nasional dalam UU RI Nomor 20 Tahun 2003, pasal 3:"Pendidikan nasional berfungsi mengembangkan kemmapuan dan membentuk waktak serta peradaban bangsa yang bermartabat dalam rangka mencerdaskan kehidupan bangsa, bertujuan untuk berkembangnya potensi peserta didik agar menjadi manusia yang beriman dan bertqwa kepada Tuhan Yang Maha Esa, berakhlak mulia, sehat, berilmu, cakap, kreatif, mandiri, dan menjadi warga negara yang demokratis serta bertanggung jawab". Sebenarnya pasal ini terlalu banyak mengandung muatan yang ingin disampaikan sehingga menjadi kabur bahkan semakin tidak jelas.

Bila dibandingkan dengan UU RI Nomor 4 Tahun 1950: "Tujuan pendidikan dan pengajaran nasional adalah, membentuk manusia susila yang cakap dan warga negara yang demokratis serta bertanggung jawab tentang kesejahteraan masyarakat dan tanah air". Rumusannya lebih sederhana, tidak berbelit, tapi memiliki makna individual, sosial, dan kebangsaan sangat dalam.Rumusan ini justru mengaitkan praksis pendidikan dengan tanggung jawab sosial, proses demokratisasi, dan pembentukan karakter bangsa (nation and character building).

Menurut Ki Hadjar Dewantara, pendidikan dimaksudkan untuk menuntun segala kekuatan kodrat yang ada pada anak didik agar mereka sebagai manusia dan sebagai anggota masyarakat dapat mencapai keselamatan dan kebahagiaan yang setinggi-tingginya. Atau dalam pandangan Driyarkara, pendidikan sebagai proses hominisasi (proses menjadikan seseorang sebagai manusia), 
dan humanisasi (proses pengembangan kemanusiaan manusia). Baik Ki Hadjar Dewantoro maupun Driyarkara menempatkan manusia sebagai subyek dari pendidikan, sehingga rumusan mengenai tujuan pengajaran dan pendidikan itu sendiri bertolak dari filsafat manusianya (Darmanigtyas, 2008:145). Rumusan ini dapat dipahami bahwa manusia dalam pendidikan tidak sebagai instrumen untuk indoktrinasi ideologi politik dan globalisasi ekonomi semata baik dalam orde baru maupun orde reformasi.

Pandangan Ki Hadjar Dewantara mengatakan pendidikan harus dibangun dengan nilai-nilai kehidupan kultural yang ada di bangsa ini (Yamin: 2005:179). Nilai-nilai kehidupan kultural nasional menjadi inti atau sentral dalam pendidikan di Indonesia. Ditanamkan nilai-nilai kultur tersebut dalam diri anak didik di rumah sebagai modal dasarnya, dan secara metodik serta sistemik dilanjutkan di sekolah kemudian diaplikasikan kembali di masyarakat. Semakin kuat nilai-nilai kultural ditanamkan maka anak bangsa ini tidak akan kehilangan identitas budaya sendiri.

Menurut Driyarkara dalam (Setiawan, 2008:85), pendidikan berarti pengangkatan manusia muda ke taraf insani sehingga dapat menjalankan hidupnya sebagai manusia utuh dan membudayakan diri. Filsafat pendidikan dalam pandangan Driyarkara mau menekankan aspek manusia, dalam hal ini manusia muda secara utuh (potensi-potensi diri: kecerdasan intelektual, emosional dan spiritual). Manusia yang cerdas intelektual, emosional dan spiritual berbasiskan pancasila sebagai landasannya. Karena nilai-nilai dalam Pancasila mencakup ketiga hal yang dapat menjadi karakter kuat bangsa Indonesia.Pancasila sebagai sumber dari segala gagasan mengenai wujud bangsa manusia dan masyarakat yang dianggap baik, sumber dari segala sumber nilai yang menjadi pangkal serta muara dari setiap keputusan dan tindakan dalam pendidikan. Pancasila sebagai sumber sistem nilai dalam pendidikan.

Demikian juga UU-RI Nomor 2 Tahun 1989, menegaskan bahwa pembangunan nasional termasuk di bidang pendidikan adalah pengamalan Pancasila, dan untuk itu pendidikan nasional mengusahakan antara lain: "Pembentukan manusia Pancasila sebagai manusia pembangunan yang tinggi kualitasnya dan mampu mandiri”.

Ideologi pendidikan haruslah berlandaskan pada Pancasila bukan pada ideologi liberaldan kapital. Terdapat dua ciri dari pendidikan yang berideologi liberal. Pertamä̈pendidikan lebih menitikberatkan pada penguasaan kompetensi yang bertujuan untuk kebutuhan dunia kerja kapitalis. Kedua, pendidikan berideologi liberal lebih menitikberatkan proses pembelajaran pada peserta didik sementara guru sekedar sebagai motivator, bukan aktor utama dalam proses pembelajaran, (Darmaningtyas, 2008:147). Ideologi ini sangat bertentangan dengan semangat nilai-nilai Pancasila.Generasi emas yang sedang dalam bangku sekolah proses pembelajarannya harus berbasis dari ideologi pancasila yang merupakan karakter bangsa yang menjamin pluralisme serta kemajemukan bangsa Indonesia. Dengan menanamkan nilai karakter yang demikianÏmaka generasi emas akan membangun hidup dan kehidupannya sesuai karakter yang ada dalam Pancasila.

Soekarno dalam (Moh Yamin, 2005:182-185) bertutur: “...sungguh alangkah hebatnya jika tiaptiap guru di Perguruan Taman Siswa itu satu persatu adalah Rasul Kebangunan...”. Terdapat dua maksud Soekarno atas "Rasul Kebangunan". Pertama, seorang guru harus memiliki modal yang luar biasa mengenai kejiwaan, keperibadian, dan budaya yang dimiliki bangsa ini apabila ingin menjadi pendidik yang sejati. Kedua, maksud dari menurunkan "kebangunan" ke dalam jiwa anak adalah kemampuan seorang pendidik untuk secara sabar dan telaten memberikan wejangan bagaimana sesungguhnya menjadi seorang anak bangsa yang bisa memberikan manfaat bagi bangsanya. Soekarno secara tegas mau mengatakan bahwa pendidik harus mengalirkan kebaikan-kebaikan dalam diri anak supaya melahirkan karakter yang baik.Kebaikan-kebaikan yang dimaksud adalah nilai kejujuran, nilai kebenaran dan nilai keadilan.Dengan demikian generasi emas yang nantinya dihasilkan 2045 adalah generasi yang berbasis pada nilai kejujuran, nilai kebenaran dan nilai keadilan yang dipayungi oleh nilai-nilai Pancasila.

\section{SOSIALISASI PANCASILA MENUJU GENERASI EMAS 2045}

Sosialisasi Pancasila menuju generasi emas 2045 sebagai pembentukan karakter bagi generasi lebih relevan dilakukan mulai dari dalam atau di rumah, di sekolah setiap mata pelajaran haruslah melandaskan diri pada nilai-nilai Pancasila dan 
dalam masyarakat melalui penataran secara kategorial. Ki Hadjar Dewantara menyebut dengan trilogi pendidikan. Keluarga, sekolah dan masyarakat menjadi motor pembentukan karakter dan mentalitas generasi emas.

Pertama, keluarga berperan penting bagi pembentukan karakter generasi emas.Kebiasaan saling menghargai, menghormati, menerima perbedaan bila dijalankan oleh orang tua di rumah justru akan membantu membentuk karakter siswa dan terbiasa dengan nilai-nilai tersebut. Maka hal yang penting dalam keluarga adalah keteladanan orang tua terhadap anak sehingga dapat membentuk mental anak secara positif.Pendidikan dalam keluarga merupakan pendidikan kodrati.Apalagi setelah anak lahir, pengenalan diantara orang tua dan anak-anaknya yang diliputi rasa cinta kasih, ketentraman dan kedamaian.

Anak-anak akan berkembang kearah kedewasaan dengan wajar dalam lingkungan keluarga segala sikap dan tingkah laku kedua orang tuanya sangat berpengaruh terhadap perkembangan anak, karena ayah dan ibu merupakan pendidik dalam kehidupan yang nyata dan pertama sehingga sikap dan tingkah laku orang tua akan diamati oleh anak baik disengaja maupun tidak disengaja sebagai pengalaman bagi anak yang akan mempengaruhi pendidikan selanjutnya. Maka, keluarga yang baik di dalamnya akan terjadi interaksi di antara para anggotanya.

Kedua, sekolah sebagai rumah kedua bagi genarasi emas yang ikut menentukan pola hidup dan kehidupan anak didik dalam interaksi sosial dan aktivitas kehidupan lainnya.Keteladan seorang guru dalam mendidik generasi emas yang berbasis nilai-nilai Pancasila sangat penting dalam mempengaruhi karakter mereka.

Sekolah adalah sebuah tempat anak bereksplorasi menjelajahi samudra pengetahuan teori maupun praktek yang berbasiskan nilai-nilai Pancasila. Sekolah sebagai lingkungan kedua harus bisa meneruskan, memperbaiki bahkan menambah apa yang telah didapatkan anak dalam lingkungan pertamanya. Sebagai contoh ketika anak telah belajar bagaimana caranya kasih sayang diungkapkan maka, pihak sekolah (Guru, Wali Kelas, BK) bisa meninjau bagaimana anak berinteraksi dengan teman-temannya untuk kemudian memberikan arahan dan bimbingan sesuai dengan tahap tumbuh kembang anak. Sekolah dalam peranannya harus bisa mengejawantahkan apa yang diamanatkan undang-undang dalam pemerataan kesempatan pendidikan dan peningkatan mutu pendidikan dalam menghadapi tantangan global.

Ketiga, masyarakat.Lingkungan masyarakat sebagai bagian dalam lingkungan pendidikan juga mempunyai andil yang besar dalam upaya mencerdaskan anak bangsa.Dalam UU No 20 Tahun 2003 tentang Sisdiknas pasal 8 tentang Hak dan Kewajiban Masyarakat dinyatakan bahwa "Masyarakat berhak berperan serta dalam perencanaan, pelaksanaan, pengawasan, dan evaluasi program pendidikan."Dalam pasal 9 dinyatakan juga bahwa Masyarakat berkewajiban memberikan dukungan sumber daya dalam penyelenggaraan pendidikan. Masyarakat dalam pasal diatas adalah kelompok warga negara Indonesia non-pemerintah yang mempunyai perhatian dan peranan dalam bidang pendidikan. Masyarakat sebagai bagian dalam sebuah sistem pendidikan harus memperlihatkan lingkungan yang memberikan tuntunan yang baik bukan tontonan yang akan merusak tatanan pendidikan yang sudah diupayakan dengan baik.

\section{SIMPULAN}

Generasi emas 2045 merupakan harapan masa depan bangsa Indonesia. Pendidikan merupakan media yang sangat sentral dalam mempersiapkan generasi emas terutama karakternya.Karakter yang harus dibangun haruslah bersifat holistik dan komprehensif berbasis pancasilais.Pendidikan tidak hanya mentransfer ilmu tetapi juga nilai-nilai terutama karakter.Karakter yang ditanamkan pada diri generasi emas haruslah berbasis tiga aspek yakni nilai kejujuran, nilai kebenaran dan nilai keadilan.

Nilai-nilai tersebut sangat bersesuaian dengan nilai-nilai Pancasila yang sangat mengedepankan nilai kejujuran, kebenaran dan keadilan dalam hidup dan kehidupan generasi emas.Proses pendidikan berbasis nilai kejujuran, kebenaran dan keadilan adalah proses pendidikan yang memanusiakan manusia. Penanaman nilainilai tersebut akan melahirkan generasi emas yang berkarakter Pancasilais berbasis budaya nasional Indonesia.

Proses sosialisasi pendidikan dapat dilakukan melalui trilogi pendidikan yakni adanya kesinambungan penanaman nilai-nilai dari keluarga sebagai sekolah pertama dalam kehidupan 
generasi emas kemudian dilanjutkan dalam sekolah sebagai tempat kedua yang sifatnya lebih sistematis, metodologis dan terkakhir dalam kehidupan sosial di masyarakat yang menjadi

\section{DAFTAR RUJUKAN}

Darmaningtyas. 2005. Pendidikan Rusak Rusakkan. Yogyakarta: LkiS Pelangi Aksara.

Darmaningtyas. 2008. Utang dan Korupsi Racun Pendidikan. Jakarta: Pustaka Yashiba.

Darmaningtyas, 2015. Pendidikan yang Memiskinkan. Malang: Instrans Publishing.

Yamin̈̈ M.2009. Menggugat Pendidikan Indonesia.Belajar dari Paulo Freire dan tuntutan generasi emas. Dengan demikian, karakter generasi emas akanterbangun yang berjiwa Pancasilais.

Ki Hadjar Dewantara. Yogyakarta: ArRuzzmedia.

Setiawan, B.. 2008. Agenda Pendidikan Nasional. Yogyakarta: Ar-Ruzzmedia.

Suparlan, S. 2006. Filsafat Pendidikan. Yogyakarta: Ar-Ruzzmedia.

Priandono T.E. Sanabila H. R. HeychaelÏ M. dan Mahendra R. 2016. Puspawarna Pendidikan Tinggi Indonesia. Jakarta: Kementerian Ristekdikti RI. 